\title{
Dysphagia is a strong predictor of death and functional dependence at three months post-stroke
}

\author{
Disfagia é um forte preditor de morte e dependência funcional três meses após acidente \\ vascular cerebral
}

\author{
Aline Cristina PACHECO-CASTILHO', Rubia Poliana Crisóstomo MIRANDA², Ana Maria Queirós NORBERTO², \\ Diandra Bosi FAVORETTO', Brunna Pileggi RIMOLI', Luciana Bezerra de Mello ALVES', \\ Karina Tavares WEBER?', Taiza Elaine Grespan SANTOS ${ }^{1}$, Julio Cesar MORIGUTI, João Pereira LEITE', \\ Roberto Oliveira DANTAS ${ }^{3}$, Rosemary MARTINO4, Octávio Marques PONTES-NETO ${ }^{1}$
}

\begin{abstract}
Background:Few Brazilianstudies investigated riskfactors for dysphagia and associated complications in a large cohort.Objective:To investigate frequency, predictors, and associated outcomes of dysphagia in patients up to three months post-stroke. Methods: Prospective cohort study of consecutively admitted patients in a specialized center for acute stroke. Patients with a transient ischemic attack, subarachnoid hemorrhage, cerebral venous thrombosis, hemorrhagic stroke with secondary cause, non-acute stroke, or those who did not consent to participate were excluded. Swallowing was evaluated by speech language pathologists using Volume-Viscosity Swallow Test. General function at three months post-stroke was assessed using the following instruments: Modified Rankin scale, Barthel Index and Functional Independence Measure. Results: A total of 831 patients were admitted and 305 patients were included according to the inclusion and exclusion criteria. The mean age of patients was $63.6 \pm 13.3$ years, mean time from stroke to swallowing assessment was $4.2 \pm 4.1$ days, and $45.2 \%$ of the patients had dysphagia. Age $(\mathrm{OR}=1.02 ; 95 \% \mathrm{Cl} 1.00-1.04 ; \mathrm{p}=0.017)$, known medical history of obstructive sleep apnea $(\mathrm{OR}=5.13 ; 95 \% \mathrm{Cl} 1.74-15.15 ; \mathrm{p}=0.003)$, and stroke severity at hospital admission $(\mathrm{OR}=1.10 ; 95 \% \mathrm{Cl} 1.06-1.15 ; \mathrm{p}<0.001)$ were independently associated with dysphagia. Dysphagia $(\mathrm{OR}=3.78$; $95 \% \mathrm{Cl} 2.16-6.61 ; \mathrm{p}<0.001)$ and stroke severity $(\mathrm{OR}=1.05 ; 95 \% \mathrm{Cl} 1.00-1.09 ; \mathrm{p}=0.024)$ were independently associated with death or functional dependence at three months. Conclusions: Dysphagia was present in almost half of stroke patients. Age, obstructive sleep apnea, and stroke severity were predictors of dysphagia, which was independently associated with death or functional dependence at three months.
\end{abstract}

Keywords: Deglutition; Deglutition Disorders; Stroke; Outcome Assessment, Health Care.

\section{RESUMO}

Antecedentes: Poucos estudos brasileiros investigaram fatores de risco para disfagia e suas complicações associadas em uma grande coorte. Objetivo: Investigar frequência, preditores e desfechos associados da disfagia em pacientes até três meses após acidente vascular cerebral (AVC). Métodos: Selecionamos pacientes admitidos consecutivamente em um centro especializado em AVC agudo. Excluímos pacientes com ataque isquêmico transitório, hemorragia subaracnóidea, trombose venosa cerebral, AVC hemorrágico de causa secundária, AVC não agudo ou aqueles que não consentiram em participar. A deglutição foi avaliada por fonoaudiólogos, por meio do teste de deglutição de volume-viscosidade. A função geral foi avaliada usando-se escala de Rankin modificada, índice de Barthel e medida de independência funcional. Resultados: Foram admitidos 831 pacientes e incluídos 305. A idade média foi 63,6 $\pm 13,3$ anos, o tempo médio da avaliação foi 4,2 44,1 dias e 45,2\% apresentavam disfagia. Idade (razão de chances [OR] 1,02; intervalo de confiança [IC95\%] 1,00-1,04; p=0,017), história médica conhecida de apneia obstrutiva do sono (OR=5,13; IC95\% 1,74-15,15; $p=0,003$ ) e gravidade do AVC na admissão hospitalar (OR=1,10; IC95\% 1,06-1,15; $p<0,001)$ foram independentemente associados à disfagia. Disfagia (OR=3,78; IC95\% 2,16-6,61; $p<0,001)$ e gravidade do AVC (OR=1,05; IC95\% 1,00-1,09; $p=0,024)$ foram independentemente associadas com morte ou dependência funcional em três meses. Conclusões: A disfagia esteve presente em quase metade dos pacientes com AVC. Idade, apneia obstrutiva do sono e gravidade do AVC foram preditores de disfagia, que esteve independentemente associada com morte ou dependência funcional em três meses.

Palavras-chave: Deglutição; Transtornos de Deglutição; Acidente Vascular Cerebral; Avaliação de Resultados em Cuidados de Saúde.

\footnotetext{
${ }^{1}$ Universidade de São Paulo, Faculdade de Medicina de Ribeirão Preto, Departamento de Neurociências e Ciências do Comportamento, Ribeirão Preto SP, Brazil. ${ }^{2}$ Universidade de São Paulo, Faculdade de Medicina de Ribeirão Preto, Departamento de Oftalmologia, Otorrinolaringologia e Cirurgia de Cabeça e Pescoço, Ribeirão Preto SP, Brazil.

${ }^{3}$ Universidade de São Paulo, Faculdade de Medicina de Ribeirão Preto, Departamento de Clínica Médica, Ribeirão Preto SP, Brazil.

${ }^{4}$ University of Toronto, Graduate Department of Rehabilitation Science, Department of Speech-Language Pathology, Toronto, Ontario, Canada. ACPC (D) https://orcid.org/0000-0003-2927-2766; RPCM (D) https://orcid.org/0000-0001-8670-5308; AMQN (D) https://orcid.org/0000-0003-1544-2330; DBF (D) https://orcid.org/0000-0001-6853-1914; BPR (D) https://orcid.org/0000-0001-7434-3127; LBMA (D) https://orcid.org/0000-0002-5068-3677; KTW (D) https://orcid.org/0000-0003-4907-8645;TEGS (iD https://orcid.org/0000-0003-3033-2981; JCM (iD https://orcid.org/0000-0001-5499-3552; JPL (D) https://orcid.org/0000-0003-4240-2393; ROD (D) https://orcid.org/0000-0003-2183-0815; RM (D) https://orcid.org/0000-0002-3298-7714; OMPN (ID) https://orcid.org/0000-0003-0317-843X

Correspondence: Aline Cristina Pacheco-Castilho; Email: alinecpacheco_usp@yahoo.com.br.

Conflict of interest: There is no conflict of interest to declare.

Authors' contributions: The authors participated sufficiently in the work to take public responsibility for appropriate portions of the content.

Support: Support from National Council of Scientific and Technological Development of Brazil (CNPq - 482721/2013-8 and 402388/2013-5) and Coordination of Improvement of Higher Education Personnel (CAPES).

Received on April 14, 2021; Received in its final form on June 21, 2021; Accepted on July 12, 2021.
} 


\section{INTRODUCTION}

Dysphagia is common in post-stroke individuals ${ }^{1}$ and contributes to worse long-term outcomes, including functional dependence ${ }^{2-5}$, institutionalization ${ }^{2,47}$ and increased mortality ${ }^{2-9}$. Some studies with stroke individuals have demonstrated that the presence of dysphagia is associated with age $^{2,5-5,10}$, female $\operatorname{sex}^{2,5,6}$, stroke severity ${ }^{2,4,5,7,8,11}$, hemorrhagic stroke $^{6,8}$, lesion in the left hemisphere ${ }^{9}$, stroke involving total anterior circulation ${ }^{6}$, stroke with involvement of the middle cerebral artery ${ }^{8}$, brain stem lesion ${ }^{10}$, prior stroke ${ }^{5,9,12}$, hypertension $^{2,5}$, diabetes ${ }^{10}$ and atrial fibrillation ${ }^{2,6,8}$. However, the factors associated with dysphagia in stroke individuals are not well established ${ }^{5,12}$.

In Brazil, the frequency of dysphagia in individuals with stroke is high compared to developed countries ${ }^{13}$. Nevertheless, only two Brazilian studies were conducted prospectively with a large sample of stroke individuals to identify the factors associated with dysphagia and the impact of dysphagia on this population ${ }^{9,14}$. In addition, these studies have explored few risk factors and did not report blinded assessments of outcomes.

Knowledge about factors associated with dysphagia and the impact of dysphagia on outcomes is important for stroke teams because it can provide information on what to expect in the assessment and prognosis of these individuals, and therefore may contribute to the planning of early preventive measures.

Thus, the aims of this study were to investigate the factors associated with dysphagia and to assess the impact of dysphagia on sub-acute clinical outcomes in stroke individuals in a large cohort prospectively and with blinded assessments of outcomes.

\section{METHODS}

\section{Design of the study}

To investigate the frequency of dysphagia and its associated factors, we performed a cross-sectional study, and to assess the impact of dysphagia on outcomes, we conducted a cohort study.

\section{Subjects}

All consecutive eligible individuals admitted to the emergency unit of a tertiary academic Brazilian hospital were approached and gave consent. Eligible individuals were those that met the following criteria: age $\geq 18$ years and had a medical diagnosis of any stroke event confirmed by CT scan and/or MRI findings. Individuals with a transient ischemic attack, subarachnoid hemorrhage, cerebral venous thrombosis, hemorrhagic stroke with secondary cause, non-acute stroke ( $>10$ days after last seen normal), or those who did not consent were excluded. This study was approved by the
Ethics Committee of our institution. Individuals that were discharged from hospital before swallowing assessment or those that were not able to be assessed due to clinical conditions were also excluded.

\section{Data source}

\section{Demographic and clinical information}

All individuals were initially screened by research coordinators as part of the admitting process with an institutionspecific stroke registry. The data were collected prospectively as per standard of care and included age, sex, premorbid functional status, potential risk factors for stroke, admission/ discharge dates, stroke details, tube feeding, overall function, and in-hospital death.

\section{Stroke characteristics}

The neuroimaging analysis was performed by neurovascular neurologists blinded to dysphagia diagnosis. The software used for analysis was Weasis v2.03. Exams were classified according to stroke type and hemisphere injured. Ischemic strokes were classified into "lacunar", "cerebellar", "cortical" and "watershed" and according to cerebral vascular territories in anterior circulation - media and anterior cerebral arteries, posterior circulation - vertebral arteries, basilar, and posterior cerebral. Stroke characteristics were analyzed independently and the same individual may have been classified into more than one topography, according to the lesion location. All individuals were also classified according to Bamford classification (total anterior circulation syndrome - TACS; partial anterior circulation syndrome - PACS; lacunar syndrome - LACS; posterior circulation syndrome - POCS $)^{15}$.

\section{Swallowing assessment}

Swallowing was evaluated by speech language pathologists (SLP) at the bedside using the Volume-Viscosity Swallow Test $(\mathrm{V}-\mathrm{VST})^{16}$. We mixed $100 \mathrm{~mL}$ of water with three measures of a xanthan-based thickener to make the pudding consistency, and with one measure to make the nectar consistency. We used increasing volumes of 5-, 10-, and 20-mL boluses in a progression of increasing difficulty as proposed in the V-VST, and the presence of dysphagia was determined according to the test results. Any sign or symptom of swallowing impairment (oral residue, reduced efficiency of labial seal, fractional swallow, and pharyngeal residue) or any sign of unsafe swallowing (cough, change in voice quality and decrease in oxygen saturation $\geq 3 \%$ ) was considered dysphagia.

\section{Outcomes}

Individuals were assessed for functional status during an outpatient clinic visit three months after stroke onset by raters blinded to dysphagia diagnosis during acute hospital 
stay. Data from individuals that died were obtained from hospital records. Functional outcomes were functional disability, assessed using the modified Rankin scale ${ }^{17}$ (mRS; 0-2: no functional dependence; 3-6: functional dependence or death), functional dependence, assessed using the Barthel Index $^{17}$ and Functional Independence Measure (FIM) ${ }^{18}$, and use of tube feeding. Individuals were also asked if they had received any rehabilitation since their stroke onset. Individuals who could not attend their outpatient clinic appointment were contacted by phone for details to inform the mRS score, the use of tube feeding and rehabilitation.

\section{Data analysis}

Clinical and demographic information were summarized descriptively using frequencies, percentages, means, standardized deviations (SD), medians and interquartile ranges (IQ). Data from individuals with and without dysphagia were compared using the t-test or Mann-Whitney test for continuous variables and chi-square or Fisher's exact test for categorical variables. Multivariate logistic regression was applied using a backward stepwise method to identify the factors associated with dysphagia and to determine if dysphagia was an independent predictor of death and or of functional dependence at three months post-stroke. All variables that presented a statistically significant difference in the univariate analysis and were potential associated factors for dysphagia and for functional dependence or death were included in the multivariate logistic regression model. We used the threshold of 0.05 for statistical significance for all analyses. Statistical analyses were performed using the software SPSS version 20.

\section{RESULTS}

A total of 831 individuals with suspected stroke were admitted to hospital between April 2015 and September 2016. Of these, 305 individuals were included based on inclusion and exclusion criteria (Figure 1). The mean age of individuals was $63.6 \pm 13.3$ years, $168(55.1 \%)$ were male, 285 (93.4\%) had an ischemic stroke, median National Institutes of Health Stroke Scale (NIHSS) score at admission was $7^{4-13}$, and 18 (5.9\%) individuals died within three months after stroke. The mean time from stroke to swallowing assessment was 4.2 \pm 4.1 days.

\section{Factors associated with dysphagia}

One hundred and thirty-eight (45.2\%) individuals had dysphagia, $54.7 \%$ of which had only safety impairments, 9.4\% had only efficacy impairments, and 35.9\% had both safety and efficacy impairments. Cough was the most frequent sign of impaired safe swallow (47.3\%) and reduced efficiency of labial seal was the most frequent sign of impaired efficacy (41.8\%). Dysphagic individuals were older (65.8 \pm 13.3 vs. $61.9 \pm 13.0$ years; $\mathrm{p}=0.010$ ) and had higher stroke severity

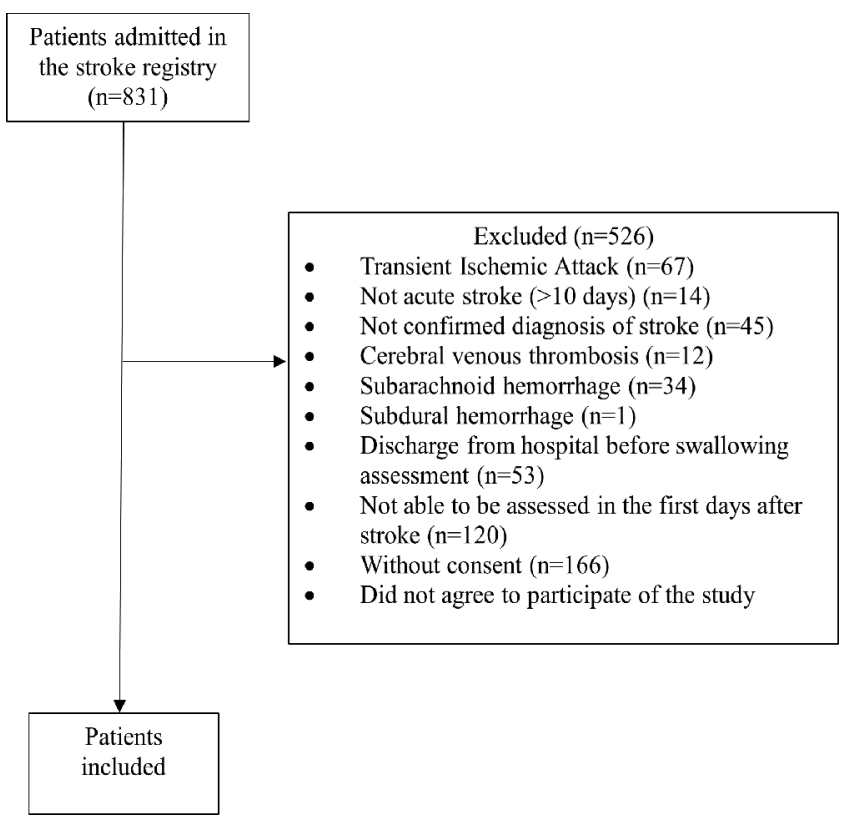

Figure 1. Flowchart of the study.

at hospital admission $\left(9^{5-17}\right.$ vs. $\left.5^{3-10} ; \mathrm{p}<0.001\right)$ than comparable individuals without dysphagia. They were also more likely to have obstructive sleep apnea (OSA) (12.3 vs. 3\%; $\mathrm{p}=0.002$ ) and TACS (18.8 vs. 9.6\%; $\mathrm{p}=0.019)$ and less likely to have LACS ( $21.7 \%$ vs. $36.5 \% ; \mathrm{p}=0.005)$ than individuals without dysphagia (Table 1). In the multivariate analysis, age $(\mathrm{OR}=1.02 ; 95 \% \mathrm{CI}$ $1.00-1.04 ; \mathrm{p}=0.017)$, medical history of OSA (OR=5.13; 95\%CI 1.74-15.15; $\mathrm{p}=0.003$ ), and stroke severity at hospital admission (OR=1.10; 95\%CI 1.06-1.15; $\mathrm{p}<0.001)$ were independently associated with dysphagia (Table 2).

\section{Outcomes}

Dysphagic individuals had longer length of hospital stay (10.0 \pm 10.2 vs. $6.7 \pm 7.8$ days; $p=0.001$ ), used tube feeding during hospitalization (65.1 vs. $18 \%$ ), had functional dependence at discharge (mRS 3-6: 54.3 vs. $22.8 \%$ ), did rehabilitation (58.2\% vs. $31.8 \%$ ), and used tube feeding ( 15.5 vs. $0.9 \%$ ) within three months more often $(\mathrm{p}<0.001$ for all comparisons) than individuals without dysphagia (Table 3). They also were more likely to die (9.4 vs. $3 \% ; \mathrm{p}=0.010$ ) and were more functionally dependent (Barthel: $71.1 \pm 33.1$ vs. $91.0 \pm 16.9$; FIM: $92.3 \pm 35.1$ vs. $114.4 \pm 19.8 ; \mathrm{p}<0.001$ ) at three months (Figure 2). Presence of dysphagia (OR=3.78; 95\%CI 2.16-6.61; $\mathrm{p}<0.001)$ and stroke severity as measure by the NIHSS scale (OR $=1.05$; $95 \%$ CI $1.00-$ 1.09; $\mathrm{p}=0.024$ ) were independently associated with death and functional dependence at three months (Table 4).

\section{DISCUSSION}

The frequency of dysphagia identified in our study is consistent with two recent cohort studies ${ }^{14,15}$, one of them in 
Table 1. Baseline characteristics of patients with and without dysphagia.

\begin{tabular}{|c|c|c|c|c|}
\hline & \multirow{2}{*}{ General $n=305$} & \multicolumn{3}{|c|}{ Dysphagia } \\
\hline & & Yes $n=138$ & No $n=167$ & $p$-value \\
\hline Age (years), mean $\pm S D$ & $63.6 \pm 13.3$ & $65.8 \pm 13.3$ & $61.9 \pm 13.0$ & $0.010 *$ \\
\hline Male sex & $168(55.1 \%)$ & $77(55.8 \%)$ & $91(54.5 \%)$ & 0.819 \\
\hline Pre-event functional dependence & $17(5.6 \%)$ & $10(7.2 \%)$ & $7(4.2 \%)$ & 0.252 \\
\hline Prior stroke & $91(29.8 \%)$ & $43(31.2 \%)$ & $48(28.7 \%)$ & 0.646 \\
\hline Hypertension & $232(76.1 \%)$ & $98(71.0 \%)$ & $134(80.2 \%)$ & 0.060 \\
\hline Diabetes & $99(32.5 \%)$ & $47(34.1 \%)$ & $52(31.1 \%)$ & 0.588 \\
\hline Dyslipidemia & $107(35.1 \%)$ & $46(33.3 \%)$ & $61(36.5 \%)$ & 0.561 \\
\hline Obstructive sleep apnea & $22(7.2 \%)$ & $17(12.3 \%)$ & $5(3.0 \%)$ & $0.002^{\star}$ \\
\hline Atrial fibrillation & $58(19.0 \%)$ & $28(20.3 \%)$ & $30(18.0 \%)$ & 0.606 \\
\hline Cardiac insufficiency & $37(12.1 \%)$ & $21(15.2 \%)$ & $16(9.6 \%)$ & 0.133 \\
\hline Obesity & $66(22.5 \%)$ & $31(23.0 \%)$ & $35(22.2 \%)$ & 0.841 \\
\hline Smoking in the past year & $82(30.0 \%)$ & $44(34.4 \%)$ & $40(26.3 \%)$ & 0.143 \\
\hline Alcoholism in the past year & $119(42.8 \%)$ & $50(39.4 \%)$ & $69(45.7 \%)$ & 0.288 \\
\hline GCS at admission, median [IQ] & $15[14-15]$ & $15[14-15]$ & $15[14-15]$ & 0.144 \\
\hline NIHSS at admission, median [IQ] & $7[4-13]$ & $9[5-17]$ & $5[3-10]$ & $<0.001^{\star}$ \\
\hline Thrombolysis or thrombectomy & $92(30.2 \%)$ & $47(34.1 \%)$ & $45(26.9 \%)$ & 0.178 \\
\hline Thrombolysis & $82(26.9 \%)$ & $42(51.2 \%)$ & $40(48.8 \%)$ & 0.180 \\
\hline Thrombectomy & $37(12.1 \%)$ & $20(54.1 \%)$ & $17(45.9 \%)$ & 0.290 \\
\hline Hemorrhagic stroke & $20(6.6 \%)$ & $11(8.0 \%)$ & $9(5.4 \%)$ & 0.365 \\
\hline Right hemisphere & $137(52.7 \%)$ & $64(55.2 \%)$ & $73(50.7 \%)$ & 0.472 \\
\hline Bamford TACS & $42(13.8 \%)$ & $26(18.8 \%)$ & $16(9.6 \%)$ & $0.019 *$ \\
\hline Bamford PACS & $131(43.0 \%)$ & $61(44.2 \%)$ & $70(41.9 \%)$ & 0.688 \\
\hline Bamford LACS & $91(29.8 \%)$ & $30(21.7 \%)$ & $61(36.5 \%)$ & $0.005^{\star}$ \\
\hline Bamford POCS & $40(13.1 \%)$ & $20(14.5 \%)$ & $20(12.0 \%)$ & 0.517 \\
\hline Anterior circulation & $263(86.2 \%)$ & $118(85.5 \%)$ & $145(86.8 \%)$ & 0.739 \\
\hline Watershed & $13(4.6 \%)$ & $5(3.9 \%)$ & $8(5.1 \%)$ & 0.651 \\
\hline Cerebellum & $18(6.3 \%)$ & $6(4.7 \%)$ & $12(7.6 \%)$ & 0.322 \\
\hline Cortical & $125(43.9 \%)$ & $57(44.9 \%)$ & $68(43.0 \%)$ & 0.755 \\
\hline Lacuna & $80(26.2 \%)$ & $31(22.5 \%)$ & $49(29.3 \%)$ & 0.174 \\
\hline
\end{tabular}

*statistically significant; GCS: Glasgow Coma Scale; NIHSS: National Institutes of Health Stroke Scale; IQ: interquartile range; SD: standardized deviation; TACS: total anterior circulation syndrome; PACS: partial anterior circulation syndrome; LACS: lacunar syndrome; POCS: Posterior circulation syndrome.

Table 2. Multivariate analysis of dysphagia predictors.

\begin{tabular}{|c|c|c|c|c|}
\hline & & OR & $95 \% \mathrm{Cl}$ & $\mathrm{p}$-value \\
\hline \multirow{5}{*}{ Step 1} & Age & 1.02 & $1.00-1.04$ & 0.021 \\
\hline & Stroke severity & 1.09 & $1.04-1.14$ & $<0.001$ \\
\hline & Obstructive sleep apnea & 5.51 & $1.84-16.49$ & 0.002 \\
\hline & TACS & 1.00 & $0.45-2.20$ & 0.986 \\
\hline & LACS & 0.66 & $0.37-1.17$ & 0.157 \\
\hline \multirow{4}{*}{ Step 2} & Age & 1.02 & $1.00-1.04$ & 0.021 \\
\hline & Stroke severity & 1.09 & $1.05-1.14$ & $<0.001$ \\
\hline & Obstructive sleep apnea & 5.50 & $1.84-16.48$ & 0.002 \\
\hline & LACS & 0.66 & $0.37-1.16$ & 0.151 \\
\hline \multirow{3}{*}{ Step 3} & Age & 1.02 & $1.00-1.04$ & 0.017 \\
\hline & Stroke severity & 1.10 & $1.06-1.14$ & $<0.001$ \\
\hline & Obstructive sleep apnea & 5.13 & $1.73-15.14$ & 0.003 \\
\hline
\end{tabular}

OR: Odds Ratio; 95\%Cl: 95\% confidence interval; TACS: total anterior circulation syndrome; LACS: lacunar syndrome. 
Table 3. Outcomes of patients with and without dysphagia.

\begin{tabular}{|c|c|c|c|c|}
\hline & \multirow{2}{*}{ General $(n=305)$} & \multicolumn{3}{|c|}{ Dysphagia } \\
\hline & & Yes $(n=138)$ & No $(n=167)$ & p-value \\
\hline Length of stay (days), mean $\pm S D$ & $8.2 \pm 9.0$ & $10.0 \pm 10.2$ & $6.7 \pm 7.8$ & 0.001 \\
\hline Use of tube feeding in hospital & $107(40.4 \%)$ & $82(65.1 \%)$ & $25(18.0 \%)$ & $<0.001$ \\
\hline \multicolumn{5}{|l|}{ mRS score at discharge } \\
\hline $0-2$ & $151(53.0 \%)$ & $41(32.3 \%)$ & $110(69.6 \%)$ & $<0.001$ \\
\hline $3-6$ & $134(47.0 \%)$ & $86(67.7 \%)$ & $48(30.4 \%)$ & \\
\hline In-hospital death & $3(1.0 \%)$ & $2(1.4 \%)$ & $1(0.6 \%)$ & 0.454 \\
\hline \multicolumn{5}{|l|}{ mRS score at 3 months } \\
\hline $0-2$ & $192(63.0 \%)$ & $63(45.7 \%)$ & $129(77.2 \%)$ & $<0.001$ \\
\hline $3-6$ & $113(37.0 \%)$ & $75(54.3 \%)$ & $38(22.8 \%)$ & \\
\hline Barthel at 3 months, mean $\pm S D$ & $82.4 \pm 27.0$ & $71.1 \pm 33.1$ & $91.0 \pm 16.9$ & $<0.001$ \\
\hline FIM at 3 months, mean $\pm S D$ & $104.9 \pm 29.5$ & $92.3 \pm 35.1$ & $114.4 \pm 19.8$ & $<0.001$ \\
\hline Death within 3 months & $18(5.9 \%)$ & $13(9.4 \%)$ & $5(3.0 \%)$ & 0.018 \\
\hline Rehabilitation within 3 months & $88(43.8 \%)$ & $53(58.2 \%)$ & $35(31.8 \%)$ & $<0.001$ \\
\hline SLP therapy & $22(12.0 \%)$ & $14(18.2 \%)$ & $8(7.5 \%)$ & 0.029 \\
\hline Physiotherapy & $66(35.9 \%)$ & $35(46.1 \%)$ & $31(28.7 \%)$ & 0.016 \\
\hline Use of tube feeding within 3 months & 14 (7.4\%) & 13 (15.5\%) & $1(0.9 \%)$ & $<0.001$ \\
\hline
\end{tabular}

SD: standard deviation; mRS: modified Rankin Scale; FIM: functional Independence Measure; SLP: speech and language pathology.

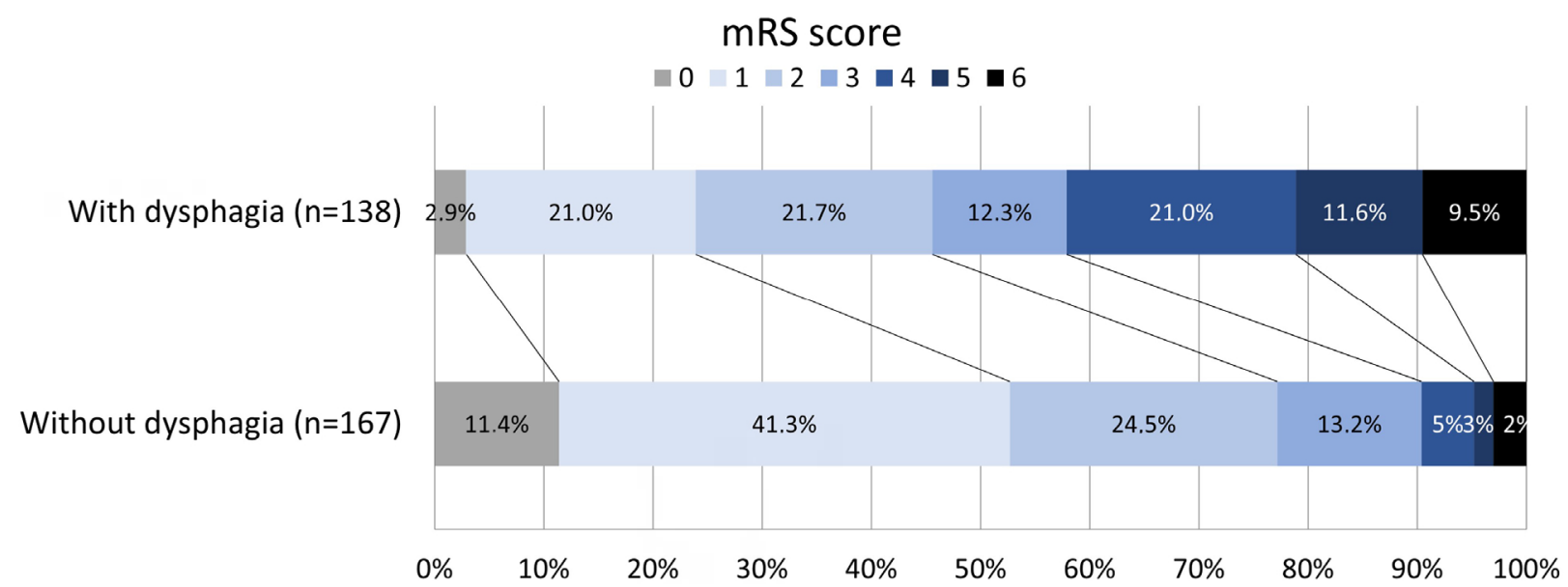

Figure 2. Modified Rankin Scale score (0 to 6; $0=$ no symptoms, $6=$ dead) at three months post-stroke in individuals with and without dysphagia diagnosed in the acute phase.

Table 4. Multivariate analysis for predictors of functional dependence or death at three months.

\begin{tabular}{|c|c|c|c|c|}
\hline & & OR & $95 \% \mathrm{Cl}$ & $\mathrm{p}$-value \\
\hline \multirow{5}{*}{ Step 1} & Age & 1.01 & $0.99-1.04$ & 0.181 \\
\hline & Stroke severity & 1.04 & $0.99-1.09$ & 0.157 \\
\hline & TACS & 1.29 & $0.55-3.00$ & 0.555 \\
\hline & LACS & 0.69 & $0.35-1.35$ & 0.279 \\
\hline & Dysphagia & 3.52 & $2.00-6.20$ & $<0.001$ \\
\hline \multirow{4}{*}{ Step 2} & Age & 1.01 & $0.99-1.04$ & 0.169 \\
\hline & Stroke severity & 1.04 & $1.00-1.09$ & 0.072 \\
\hline & LACS & 0.67 & $0.35-1.31$ & 0.243 \\
\hline & Dysphagia & 3.53 & $2.00-6.20$ & $<0.001$ \\
\hline \multirow{3}{*}{ Step 3} & Age & 1.01 & $0.99-1.04$ & 0.153 \\
\hline & Stroke severity & 1.05 & $1.01-1.10$ & 0.022 \\
\hline & Dysphagia & 3.60 & $2.05-6.32$ & $<0.001$ \\
\hline \multirow{2}{*}{ Step 4} & Stroke severity & 1.05 & $1.01-1.09$ & 0.024 \\
\hline & Dysphagia & 3.78 & $2.16-6.61$ & $<0.001$ \\
\hline
\end{tabular}

TACS: total anterior circulation syndrome; LACS: lacunar syndrome. 
Brazil ${ }^{14}$. However, it was lower than the frequency of dysphagia estimated in a systematic review of Brazil [13], probably because we did not include severely affected individuals who could not be evaluated in the first days after the stroke.

The results of our study confirm the association of dysphagia with age and stroke severity reported in the literature ${ }^{5,11,14,19-21}$. Thus, among the many factors associated with dysphagia in stroke individuals, age and stroke severity are strong risk factors for dysphagia. Therefore, older individuals and those with more severe strokes should be monitored more carefully due to the risk of developing dysphagia and its associated complications.

An important finding in our study was the association between OSA and dysphagia. OSA is an important risk factor for stroke $e^{22-24}$, being common in this population. It is also associated with changes in swallowing ${ }^{25-28}$. However, to date, no study has investigated whether individuals with stroke and OSA are at greater risk of developing dysphagia than individuals with stroke without OSA. In our study, OSA was an independent risk factor for dysphagia, so these individuals are more likely to develop dysphagia after a stroke. Thus, all stroke patients with OSA should be assessed for orofacial muscles and swallowing, as they have more chances to have dysphagia compared to stroke individuals without OSA.

Our study also confirmed that dysphagia in stroke patients in Brazil has an important impact on length of stay, mortality, and outcomes ${ }^{9,14}$. This highlights the importance of promoting adequate management strategies for dysphagia in Brazilian guidelines to avoid poor outcomes in this population.

Thus, this study provides important epidemiological data for stroke care in Brazil to help identify individuals at risk for dysphagia and to demonstrate the impact of dysphagia on this population. This highlights the importance of promoting better management strategies for these individuals to prevent poor outcomes. These strategies include screening for early detection of dysphagia and referring individuals who do not have it for evaluation by speech therapists.

There are some limitations in this study. Data about risk factors for stroke were collected from the medical history reported by the individual or his or hers caregiver. However, the presence of risk factors such as OSA was considered only if the diagnosis was confirmed or if the person was taking medication for the condition. We did not evaluate more severe stroke individuals because we only assessed individuals in the first few days after hospital admission, and severe patients could not be assessed at that time. Despite this, we could identify a high rate of dysphagia and associations with poor outcomes.

Despite these limitations, our study was performed prospectively and consecutively, with a large cohort of stroke individuals, and all individuals were assessed in a standardized way by SLP. The outcomes were assessed blindly for dysphagia diagnosis, which contributes to the reliability of the observed results.

This study confirms that dysphagia is frequent in poststroke individuals and is a strong predictor of death or functional dependence. Stroke teams should be alert for increased risk of dysphagia in the elderly or those with OSA. Brazilian health managers should be aware of the need to implement strategies for early detection and management of dysphagia to avoid poor outcomes.

\section{ACKNOWLEDGEMENT}

We thank the REAVER team for collaborating with participant recruitment and for acquiring demographic and clinical data.

\section{References}

1. Martino R, Foley N, Bhogal S, Diamant N, Speechley M, Teasell R. Dysphagia after stroke: incidence, diagnosis, and pulmonary complications. Stroke. 2005 Dec;36(12):2756-63. https://doi. org/10.1161/01.STR.0000190056.76543.eb

2. Joundi RA, Saposnik G, Martino R, Fang J, Kapral MK. Predictors and outcomes of dysphagia screening after acute ischemic stroke. Stroke. 2017 Apr;48(4):900-6. https://doi.org/10.1161/ STROKEAHA.116.015332

3. Al-Khaled M, Matthis C, Binder A, Mudter J, Schattschneider J, Pulkowski $U$, et al. Dysphagia in individuals with acute ischemic stroke: early dysphagia screening may reduce stroke-related pneumonia and improve stroke outcomes. Cerebrovasc Dis. 2016 Jun;42(1-2):81-9. https://doi.org/10.1159/000445299

4. Arnold M, Liesirov K, Broeg-Morvay A, Meisterernst J, Schlager M, Mono ML, et al. Dysphagia in acute stroke: incidence, burden and impact on clinical outcome. PLoS One. 2016 Feb;11(2):e0148424. https://doi.org/10.1371/journal.pone.0148424

5. Rofes L, Muriana D, Palomeras E, Vilardell N, Palomera E, AlvarezBerdugo D, et al. Prevalence, risk factors and complications of oropharyngeal dysphagia in stroke individuals: A cohort study. Neurogastroenterol Motil. 2018 Mar;e13338. https://doi.org/10.1111/ nmo.13338

6. Smithard DG, Smeeton NC, Wolfe CD. Long-term outcome after stroke: does dysphagia matter? Age Ageing. 2007 Jan;36(1):90-4. https://doi.org/10.1093/ageing/afl149

7. Bonilha HS, Simpson AN, Ellis C, Mauldin P, Martin-Harris B, Simpson K. The one-year attributable cost of post-stroke dysphagia. Dysphagia. 2014 Oct;29(5):545-52. https://doi.org/10.1007/s00455-014-9543-8

8. Paciaroni M, Mazzotta G, Corea F, Caso V, Venti M, Milia P, et al. Dysphagia following stroke. Eur Neurol. 2004;51(3):162-7. https://doi. org/10.1159/000077663

9. Baroni AF, Fábio SR, Dantas RO. Risk factors for swallowing dysfunction in stroke individuals. Arq Gastroenterol. 2012 Apr-Jun;49(2):118-24. https://doi.org/10.1590/S0004-28032012000200005

10. Remesso GC, Fukujima MM, Chiappetta AL, Oda AL, Aguiar AS, Oliveira A de S, et al. Swallowing disorders after ischemic stroke. Arq Neuro-Psiquiatr. 2011 Oct;69(5):785-9. https://doi.org/10.1590/ s0004-282x2011000600012 
11. Okubo PC, Fábio SR, Domenis DR, Takayanagui OM. Using the National Institute of Health Stroke Scale to predict dysphagia in acute ischemic stroke. Cerebrovasc Dis. 2012 Apr;33(6):501-7. https://doi.org/10.1159/000336240

12. Mourão AM, Lemos SM, Almeida EO, Vicente LC, Teixeira AL. Frequency and factors associated with dysphagia in stroke. Codas. 2016 JanFeb;28(1):66-70. https://doi.org/10.1590/2317-1782/20162015072

13. Pacheco-Castilho AC, Vanin GM, Dantas RO, Pontes-Neto OM, Martino R. Dysphagia and associated pneumonia in stroke patients from Brazil: a systematic review. Dysphagia. 2019 Aug;34(4):499-520. https://doi.org/10.1007/s00455-019-10021-0

14. Souza JT, Ribeiro PW, Paiva SAR, Tanni SE, Minicucci MF, Zornoff LAM, et al. Dysphagia and tube feeding after stroke are associated with poorer functional and mortality outcomes. Clin Nutr. 2020 Sep;39(9):2786-92. https://doi.org/10.1016/j.clnu.2019.11.042

15. Lindley RI, Warlow CP, Wardlaw JM, Dennis MS, Slattery J, Sandercock PA. Interobserver reliability of a clinical classification of acute cerebral infarction. Stroke. 1993 Dec;24(12):1801-4. https:// doi.org/10.1161/01.str.24.12.1801

16. Rofes L, Arreola V, Mukherjee R, Clavé P. Sensitivity and specificity of the Eating Assessment Tool and the Volume-Viscosity Swallow Test for clinical evaluation of oropharyngeal dysphagia. Neurogastroenterol Motil. 2014 Sep;26(9):1256-65. https://doi. org/10.1111/nmo.12382

17. Cincura C, Pontes-Neto OM, Neville IS, Mendes HF, Menezes DF, Mariano DC, et al. Validation of the National Institutes of Health Stroke Scale, modified Rankin Scale and Barthel Index in Brazil: the role of cultural adaptation and structured interviewing. Cerebrovasc Dis. 2009;27(2):119-22. https://doi.org/10.1159/000177918

18. Riberto M, Miyazaki MH, Jucá SSH, Sakamoto H, Pinto PPN, Battistella LR. Validation of the Brazilian version of Functional Independence Measure. Acta Fisiatr. 2004 Jun;11(2): 72-6. https:// doi.org/10.1590/0004-282X20140066

19. Sporns PB, Muhle P, Hanning U, Suntrup-Krueger S, Schwindt W, Eversmann $\mathrm{J}$ et al. Atrophy of swallowing muscles is associated with severity of dysphagia and age in individuals with acute stroke. J Am Med Dir Assoc. 2017 Jul;18(7):635.e1-635.e7. https://doi. org/10.1016/j.jamda.2017.02.002

20. Labeit B, Mueller H, Muhle P, Claus I, Warnecke T, Dziewas R, et al. Predicting dysphagia with national institute of health stroke scale: distinction between infra- and supratentorial region is essential. Cerebrovasc Dis. 2018;46(3-4):152-60. https://doi. org/10.1159/000493371

21. Henke C, Foerch C, Lapa S. Early screening parameters for dysphagia in acute ischemic stroke. Cerebrovasc Dis. 2017;44(5-6):285-90. https://doi.org/10.1159/000480123

22. Javaheri S, Barbe F, Campos-Rodriguez F, Dempsey JA, Khayat R, Javaheri S, et al. Sleep apnea: types, mechanisms, and clinical cardiovascular consequences. J Am Coll Cardiol. 2017 Feb;69(7):84158. https://doi.org/10.1016/j.jacc.2016.11.069

23. Stevens D, Martins RT, Mukherjee S, Vakulin A. Post-stroke sleepdisordered breathing-pathophysiology and therapy options. Front Surg. 2018 Feb;5:9. https://doi.org/10.3389/fsurg.2018.00009

24. Sharma S, Culebras A. Sleep apnea and stroke. Stroke Vasc Neurol. 2016 Dec;1(4):185-91. https://doi.org/10.1136/svn-2016-000038

25. Valbuza JS, de Oliveira MM, Zancanella E, Conti CF, Prado LB, Carvalho LB, et al. Swallowing dysfunction related to obstructive sleep apnea: a nasal fibroscopy pilot study. Sleep Breath. 2011 May;15(2):209-13. https://doi.org/10.1007/s11325-010-0474-9.

26. Oliveira LA, Fontes LH, Cahali MB. Swallowing and pharyngoesophageal manometry in obstructive sleep apnea. Braz J Otorhinolaryngol. 2015 May-Jun;81(3):294-300. https://doi. org/10.1016/j.bjorl.2015.03.006

27. Jäghagen EL, Berggren D, Isberg A. Swallowing dysfunction related to snoring: a videoradiographic study. Acta Otolaryngol. 2000 Apr;120(3):438-43. https://doi.org/10.1080/000164800750000702

28. Buterbaugh J, Wynstra C, Provencio N, Combs D, Gilbert M, Parthasarathy $S$. Cerebrovascular reactivity in young subjects with sleep apnea. Sleep. 2015 Feb;38(2):241-50. https://doi.org/10.5665/ sleep.4406 